\title{
A determinação do limite da razão e a doutrina kantiana do Facto da Razão
}

\section{The determination of the limits of reason and Kant's doctrine of the Fact of reason}

\section{SOLANGE DEJEANNE}

Resumo: No trabalho, busca-se evidenciar que os argumentos de Kant, acerca da fundamentação do princípio supremo da moralidade, fazem-se sempre em vista da unidade da razão (pura), uma exigência do próprio método kantiano. Além disso, ressaltam-se as implicações dessa exigência de coerência sistemática, imposta pelo método transcendental ao projeto (crítico) da fundamentação de uma metafísica dos costumes. Ao considerar que, na execução deste projeto, Kant não negligenciou, em momento algum, as restrições da Crítica da razão pura para tal tarefa, defende-se a tese, segundo a qual, o próprio limite da razão constitui-se lugar justificado para uma lei moral, considerado o facto puro da razão. Nesta leitura, é conferido, à doutrina do facto da razão, um respaldo crítico que, à primeira vista, pode parecer ausente da solução kantiana para o problema em questão.

Palavras-chave: Método crítico. Sistema da razão pura. Liberdade transcendental.

Abstract: This work, seeks to show that Kant's arguments, on behalf of the grounds of the Supreme principle of morality are always presented in view the unity of reason (pure), a requirement of Kant's method itself. In addition, points out the implications of this systematic consistency requirement, imposed by the transcendental method to the project (critical) of the statement of reasons of a metaphysics of morals. Considering that, during accomplishment of this project, Kant didn't overlooked at any time, the restrictions of the Critique of pure reason, we put forth the thesis,

1 Doutora em Filosofia pela Pontifícia Universidade Católica do Rio Grande do Sul PUC/RS. Professora Adjunta do Centro Universitário Franciscano de Santa Maria, RS. Ex-bolsista do PET/Filosofia da UNIOESTE (1993-94). 
according to which, the very limit of reason is justified to place a moral law, considered the fact pure of reason. In this reading, is conferred, to the doctrine of the fact of reason, a critical support that, at first glance, it may seem absent from the Kant's solution to the problem in question.

Keywords: Critical method. System of pure reason. Transcendental freedom.

\section{Introdução}

O lugar que a doutrina do facto da razão, apresentada por Kant na Analítica da Crítica da razão Prática ${ }^{2}$, ocupa no sistema da filosofia crítica parece merecer atenção redobrada dos leitores do texto kantiano. Entretanto, as razões para redobrarmos nossa atenção sobre essa temática não se encontram apenas na recepção um tanto negativa que a segunda Crítica obteve já dos primeiros comentadores da ética kantiana. É o próprio texto de Kant que impõe ao seu leitor tal cuidado. No início do Prefácio da referida Crítica, nota-se a pretensão do autor de que, com a solução do problema da fundamentação do princípio supremo da moralidade, também se estabeleça a pedra angular de todo sistema da razão pura. Tal "pedra angular", como sabem os conhecedores de texto em questão, é a própria ideia da liberdade, a qual, de acordo com Kant, tem sua realidade provada mediante a comprovação da capacidade legisladora da razão prática pura.

${ }^{2}$ Kant, I. Crítica da razão prática. Trad. Artur Morão. Lisboa: Edições 70, 1994. Doravante será indicada nas citações pela sigla CRPr, seguida da paginação original indicada pelo tradutor. 
Com esta faculdade [da razão prática pura], fica também agora solidamente estabelecida a liberdade transcendental e tomada, sem dúvida, no sentido absoluto de que a razão especulativa precisava, no uso do conceito de causalidade, para se subtrair à antinomia em que inevitavelmente cai quando, na série da conexão causal, ela quer pensar o incondicionado; mas [a razão especulativa] só podia estabelecer esse conceito problematicamente, como não impossível de pensar, sem lhe assegurar sua realidade objetiva [...]. O conceito de liberdade, na medida em que a sua realidade é demonstrada por uma lei apodíctica da razão prática, constitui a pedra angular de todo o edifício de um sistema da razão pura, mesmo da razão especulativa [...] (CRPr, A 4$)$.

Contudo, nesse mesmo contexto o autor também adverte seu leitor de que a razão prática pura com seu peculiar princípio, qual seja a lei moral, não serve de escora para o sistema da razão pura especulativa, como se este não fosse capaz de manter-se em seus fundamentos próprios. Isso porque o sistema da razão pura especulativa já fora concluído e fundamentado, não obstante as restrições da crítica com relação à questão do incondicionado. Por isso, aos familiarizados com a Crítica da razão pura ${ }^{3}$ não é dado esperar da segunda Crítica um conhecimento, no sentido estrito do termo, de um princípio absoluto (totalmente a priori) da razão pura, ainda que em seu uso prático. Assim, como entender a pretensão de Kant de estabelecer, solidamente, um conceito/princípio problemático para a razão especulativa a partir de "uma lei apodítica da razão prática”? Parece que a resposta a esta pergunta só pode ser encontrada

${ }^{3}$ Kant, I. Crítica da razão pura. Trad. Alexandre Fradique Morujão e Manuela Pinto dos Santos. 3 ed. Lisboa: Calouste Gulbenkian, 1994. A partir de agora referida nas citações pela sigla CRP, seguida da paginação original indicada pelos tradutores. 
satisfatoriamente se insistirmos em uma leitura que leve em conta o caráter sistemático do pensamento kantiano e que se apresenta como tal porque considera que a própria razão (pura) constitui-se em um sistema de princípios a priori $^{4}$.

Já, no Prefácio da Primeira Edição da Crítica da Razão Pura, a tarefa primordial da Crítica é resolver todos os problemas da razão. Trata-se, pois, de uma crítica "da faculdade da razão em geral, com respeito a todos os conhecimentos a que a razão pode aspirar, independentemente de toda a experiência [...] tudo isto, contudo, a partir de princípios" (CRP, A XII). Então, julgando ter resolvido pela Crítica todos os problemas metafísicos ou, pelo menos, ter fornecido a chave da solução de tais problemas, Kant sentencia: "Com efeito, a razão pura é uma unidade tão perfeita que, se o seu princípio não fosse suficiente para resolver uma única questão de todas aquelas que lhe são propostas pela sua natureza, haveria que rejeitá-lo, pois não se poderia aplicar a qualquer outra com perfeita segurança” (A XIII). Ocorre porém, que nessa sua tarefa crítica, primordial de resolver todos os problemas da razão, muito provavelmente com a pretensão de evidenciar a ideia da unidade da razão pura a partir de princípios, Kant acaba tendo que reconhecer, por assim dizer, dois sistemas da razão, a saber, o sistema da filosofia teórica e o (sistema) da filosofia prática, com seus respectivos princípios. Logo, uma importante questão, que resta ao leitor de Kant, é justamente investigar se e como os princípios da razão teórica e o princípio prático se articulam em um único sistema da razão, concebido pelo método crítico-

\footnotetext{
${ }^{4}$ Com isso não se quer aqui entrar na problemática da unidade da razão.
} 
transcendental ${ }^{5}$. Aqui não se aborda exatamente essa problemática, mas trata-se de pô-la em perspectiva em vista da solução da questão da justificação do princípio supremo da moralidade.

Se considerarmos a importância que a questão da fundamentação de tal princípio adquire no percurso do pensamento crítico, e todo esforço de Kant nessa tarefa, forçoso é reconhecer que a coerência da filosofia kantiana depende, em boa medida, da congruência dos princípios fundamentais que dão sustentação aos sistemas da razão teórica e prática. Ora, esta questão parece implicar justamente na coerência crítica das estratégias de prova da validade e realidade objetiva de tais princípios. Neste texto, de acordo com o tema indicado no título, não se trata aqui da dedução transcendental dos conceitos puros do entendimento. Não que não se possa problematizar tal tarefa, que exigiu de Kant seu maior esforço e cujo reconhecimento é indiscutível, mas o que interessa particularmente, a questão que se nos apresenta, é o argumento de Kant com relação à (pretendida) prova da validade objetiva de um princípio prático puro, bem como o lugar que este princípio ocupa no sistema da razão pura afinal, conforme já citado, é com a prova da validade desse princípio que se estabelece a pedra angular de todo sistema da razão pura, a

${ }^{5}$ No Prefácio da segunda Crítica, Kant trata ligeiramente da questão do sistema da razão pura em termos de análise e síntese das partes "de uma faculdade particular da alma humana, segundo as suas fontes, conteúdos e limites" (CRPr, A 18). Na determinação dessa faculdade Kant diz haver um "motivo de atenção" que é "arquitetônico, a saber, apreender a ideia do todo e, a partir dela, perspectivar na faculdade da razão pura todas aquelas partes na sua relação recíproca, mediante a derivação das mesmas a partir do conceito do todo. Este exame e esta garantia só são possíveis mediante o conhecimento mais íntimo do sistema;" ( A 18-19). Quanto ao conhecimento do sistema, Kant diz que ele implica uma "[...] visão global, que é um retorno sintético ao que antes foi fornecido pela análise” (A 19). 
saber, a liberdade transcendental (cf. CRPr, A 4). Sobre este aspecto do pensamento kantiano, nota-se como legítima e profícua a preocupação (e ocupação) da literatura secundária com respeito à situação da doutrina do facto da razão no contexto da filosofia crítica ${ }^{6}$.

Grande parte das interpretações referentes à doutrina do facto da razão, no que diz respeito ao "procedimento de prova" da validade objetiva (e da necessidade prática) do que Kant considera o princípio supremo da moralidade, sustenta que o argumento desenvolvido por ele na Crítica da razão prática constitui-se como novidade em relação ao argumento apresentado na Fundamentação da metafisica dos costumes $^{7}$. Com efeito, sobre o problema da fundamentação de um princípio moral universalmente válido, é frequente, na literatura secundária recente, a tese, segundo a qual na segunda Crítica, Kant teria abandonado toda e qualquer tentativa de deduzir a lei da moralidade para, finalmente, propor a doutrina do facto da razão como uma espécie de substituta para a tentativa (supostamente fracassada) de uma dedução (transcendental) dessa lei ${ }^{8}$. De acordo

${ }^{6}$ Entre os estudiosos do pensamento kantiano no Brasil, encontramos essa preocupação nos escritos do prof. Z. Loparic, que em seu artigo "O Fato da razão uma interpretação semântica", publicado em 1999 pela Analytica, faz preceder sua interpretação semântica do fato da razão por um tópico que manifesta seu propósito "de uma melhor compreensão do fato da razão no quadro da obra de Kant" (vol. 4, n. 1, p. 21-24). Cf. a respeito também o artigo "A doutrina do facto da razão no contexto da filosofia crítica kantiana” de A. Faggion, publicado na Studia Kantiana (vol.6/7, 2008).

${ }^{7}$ Kant, I. Fundamentação da metafísica dos costumes. Trad. Paulo Quintela. Lisboa: Edições 70, 1994. Doravante indicada nas citações pela sigla FMC, seguida da paginação original indicada pelo tradutor.

${ }^{8}$ Cláudio Dalbosco lembra-nos que, em meados dos anos setenta do século passado, Dieter Henrich, "ainda que de modo cauteloso e um pouco cético, toma partido a favor da tese de que a teoria do 'Faktum der Vernunft' é apresentada por Kant como 
com essa tendência interpretativa, Kant teria solucionado o problema da fundamentação do princípio moral apenas no texto de 1788, haja vista a impossibilidade de uma dedução desse princípio. Nesse contexto, Kant teria reconhecido finalmente que tal dedução seria, além de impossível, desnecessária?.

Observa-se assim que a leitura predominante é de que, com a figura do facto da razão, nosso filósofo teria subvertido as supostas tentativas de uma dedução do princípio moral supremo e afirmado, simplesmente, a (consciência da) lei moral como o "único facto puro da razão". Mas, seria a teoria do fato da razão realmente um atestado

uma alternativa ao seu propósito de dedução da lei moral, levado adiante na Grundlegung. [E que] Inspirado em Henrich, anos mais tarde, Allison (1995), [...] defendeu a descontinuidade entre a dedução do imperativo categórico e a teoria do 'Faktum der Vernunft', consolidando, com isso, entre os comentaristas, a tese interpretativa do abandono da solução da Grundlegung a favor da teoria do 'Faktum der Vernunf" (“'Círculo vicioso' e idealismo transcendental na Grundlegung”, Studia Kantiana, vols. 6/7, p. 208). No Brasil essa tese foi seguida tanto por Z. Loparic quanto por Guido de Almeida, cujas interpretações do problema kantiano da fundamentação do princípio supremo da moralidade se tornaram já imprescindíveis aos estudiosos da ética kantiana.

${ }^{9}$ É notável a esse respeito que a posição defendida por Cláudio Dalbosco, no seu artigo "'Círculo vicioso' e idealismo transcendental na Grundlegung" (cf. nota anterior), constitui-se em uma leitura alternativa a esta interpretação, bastante generalizada, de que na Fundamentação há uma tentativa frustrada de dedução da lei moral, e por isso abandonada por Kant em favor da doutrina do facto da razão. Apesar de não se ocupar em seu texto explicitamente com a doutrina do facto da razão, a tese de Dalbosco acerca dos argumentos que Kant apresenta na Fundamentação é de que já nesse contexto ele leva a cabo a dedução da lei moral como imperativo categórico (cf. p. 231). De acordo com sua leitura, cuja tese é de que, já em 1785, com base no idealismo transcendental, Kant apresenta efetivamente a solução da dedução da lei moral como imperativo categórico, pois a teoria do Faktum der Vernunft não é outra coisa senão apenas a "continuidade e aprofundamento" de uma solução já apresentada previamente e não uma alternativa a uma (suposta) "solução fracassada" (cf. p. 210). 
do fracasso e, consequentemente, do abandono do programa de uma dedução da lei moral que o filósofo teria empreendido na Fundamentação da metafísica dos costumes? ${ }^{10}$ Neste contexto, defende-se tese contrária. Mas não só isso. Trata-se, em especial, de mostrar que a doutrina do facto da razão satisfaz plenamente as exigências impostas à razão pela Crítica quanto a permanecer dentro de seu próprio limite.

Nos argumentos que Kant desenvolve na Fundamentação da metafísica dos costumes III, sua pretensão parece ser mesmo apresentar uma prova da validade objetiva do imperativo categórico a partir de uma dedução. Contudo, ao julgar confirmada a "exatidão desta dedução" (FMC, BA 112), o filósofo não a explicita e parece não pretender que ela seja nos termos da dedução das categorias, isto é, transcendental stricto sensu", por assim dizer. Quão problemática seria uma dedução do princípio da moralidade (ou da liberdade em

${ }^{10}$ Este é o questionamento (também) de Dalbosco, após algumas considerações acerca das posições de D. Henrich, H. Allison e Guido Antonio de Almeida em relação ao "lugar que a Grundlegung ocupa em relação à Crítica da razão prática" (p. 208), posições essas que defendem uma descontinuidade entre as soluções para o problema da fundamentação do princípio moral que Kant apresenta nas duas obras referidas: "[...] se a teoria do 'Faktum der Vernunft' precisa realmente ser interpretada como um abandono do programa de fundamentação da lei moral levada adiante na Grundlegung e se nessa obra, a dedução do imperativo categórico depende, como supõe a interpretação de [Guido de] Almeida, de uma prova de validade do conceito de liberdade" (p. 209).

"Sobre a diversidade dos usos do termo "dedução" nos escritos de Kant, cf. Adela Cortina, "Estudio Preliminar" a La Metafísica de las Costumbres", in.: Kant, I. La Metafisica de las Costumbres. Trad. Adela Cortina e Jesus Conill Sancho. Madrid: Tecnos, 1989 . 
sentido positivo) nos termos da dedução transcendental das categorias, pois o leitor atento ao argumento da dedução na primeira Crítica pode por si só perceber isso. Com efeito, é difícil conceber que depois de todo o esforço de preparação e elaboração desse magnífico trabalho (para dizer o mínimo), que é a Crítica da razão pura, Kant tivesse simplesmente negligenciado os resultados de seu empenho ao examinar, criteriosa e rigorosamente, o uso legítimo dos conceitos puros do entendimento. É difícil imaginar que, mesmo sendo para justificar o princípio supremo da moralidade - indiscutivelmente um tema caro a Kant - o filósofo tivesse ousado ultrapassar os limites da razão por ele mesmo estabelecidos, em sua primeira Crítica, a custo de muito trabalho! Mesmo assim, o texto da Terceira Secção da Fundamentação se presta a diferentes leituras e há uma diversidade de estudos existentes sobre esta questão sustentando que a dedução da lei moral pretendida por Kant, em 1785, foi entendida nos termos da dedução dos conceitos puros do entendimento ${ }^{12}$.

${ }^{12}$ Com efeito, entre os problemas e dificuldades apontados pelos estudiosos da Terceira Secção da Fundamentação, encontra-se a questão do caráter da dedução para o princípio da moralidade. Tendo em vista o modelo da dedução transcendental das categorias do entendimento, bem como a natureza do princípio supremo da moralidade, uma proposição prática sintética a priori, a qual não pode ser "provada" na e pela experiência, o problema implicado na questão seria o da natureza mesma da dedução de tal princípio. Ou seja, a polêmica em torno do conceito de "dedução", usado por Kant na Terceira Secção da Fundamentação, se estabelece em vista do próprio modelo de dedução das categorias, que não pode ser aplicado à ideia de liberdade que, por sua vez, dá sustentação à lei da moralidade. Além disso, parece pairar uma dúvida quanto ao próprio objeto da dedução, se a liberdade ou se a própria lei moral. De qualquer modo, a distinção de Dieter Henrich entre os conceitos "forte" e "fraco" de dedução, e sua tese de que "[...] o conceito de dedução da Grundlegung não pode ser parte de uma dedução no sentido originário e forte do termo, isto é, da dedução transcendental das categorias" (apud Dalbosco, p. 
Uma alternativa possível a essa interpretação, mesmo admitindo que Kant tenha pretendido apresentar na Fundamentação III uma dedução do princípio da moralidade, é considerar que o termo "dedução", tal como empregado nesse contexto, implica um sentido amplo, o sentido do quid juris em geral de um princípio qualquer (no caso, do princípio moral) e não significa apenas o procedimento metódico adequado para provar o quid juris dos conceitos puros do entendimento na sua aplicação aos dados da sensibilidade. $O$ problema com essa leitura é que Kant não faz qualquer referência ao sentido amplo de uma dedução no contexto de explicação da lei moral, apesar de referir-se à "exatidão desta dedução". Assim, estando os leitores do texto kantiano familiarizados com a dedução transcendental das categorias e não reconhecendo nenhuma dedução em sentido amplo, expõe-se o problema para os intérpretes: afinal, Kant apresenta ou não uma dedução do princípio moral na Fundamentação?

Por suporem que Kant estivesse tentando uma dedução do princípio supremo da moralidade nos mesmos termos da dedução transcendental das categorias, alguns estudiosos da Fundamentação concluíram (coerentemente) que Kant havia fracassado em sua empreitada, e mais do que isso, que ele mesmo havia reconhecido seu

208), pode ajudar amenizar esta polêmica. Particularmente, não vejo como provável, sequer razoável, que Kant tenha tentado uma dedução "forte" do princípio da moralidade que afinal consiste em uma ideia da razão (tendo em vista aqui a equivalência entre "liberdade" e "lei da moralidade"), depois de todas as considerações na primeira Crítica acerca da especificidade da dedução das ideias da razão. 
fracasso $^{13}$. E não só isso. Em geral, a mesma interpretação, segundo a qual, Kant teria fracassado em sua proposta de uma dedução do princípio moral, é complementada pela hipótese de que o filósofo, ao reconhecer o fracasso de sua empresa, teria abandonado o projeto da fundamentação da metafísica dos costumes por via da dedução, porem sem abandonar o próprio projeto da fundamentação da moral, o que teria resultado na doutrina do facto da razão na segunda Crítica.

Parece indiscutível o fato de Kant ter reconhecido, na Fundamentação III, a incapacidade da razão humana explicar "como uma razão pura possa ser prática" (cf. BA 125). Todavia, deve esse reconhecimento ser entendido como se o filósofo admitisse também o fracasso de sua tentativa de apresentar uma justificação para o princípio da moralidade? Quem aposta em uma resposta afirmativa a esta questão precisa solucionar outro problema: o inusitado (da doutrina) do facto da razão em relação a uma "autêntica dedução crítica”. Em vista disso, os estudiosos da ética kantiana também já apontaram, com propriedade, todas as dificuldades que cercam a doutrina aqui referida, a ponto mesmo de questionar o caráter genuinamente crítico desse elemento importante do sistema da filosofia prática de Kant. Ora, qualquer que seja a interpretação acerca da doutrina do fato da razão, a análise desse fragmento do pensamento kantiano, apresentado na Crítica da razão prática, parece mesmo implicar, em boa medida, a consideração dos argumentos que Kant apresenta na Fundamentação - se não for por outro motivo - será pela simples razão de que, em ambos os textos, trata-se da mesma

\footnotetext{
${ }^{13}$ Exemplo disso são as considerações do prof. Z. Loparic no contexto em que ele trata das "Questões não resolvidas na Fundamentação", no seu artigo, "O Fato da razão - uma interpretação semântica” (Analytica, vol. 4, n. 1, 1999, p. 30-31).
} 
problemática implicada na questão da fundamentação do princípio moral.

Com isso nota-se que a questão a ser respondida pelos leitores e estudiosos, que procuram compreender o pensamento kantiano no que diz respeito à proposta de fundamentação do princípio moral, desde sua perspectiva crítico-sistemática, não é simplesmente a que diz respeito ao êxito ou fracasso do argumento apresentado na Terceira Seção da Fundamentação, ou à continuidade ou ruptura entre o argumento que Kant apresenta na Fundamentação III e o (argumento) que ele desenvolve na segunda Crítica. Trata-se, fundamentalmente, de verificar se o fato da razão pode ser considerado um elemento criticamente estabelecido, dado o caráter aparentemente inusitado desta figura diante da investigação críticotranscendental empreendida por Kant na Crítica da razão pura.

Aqui importa defender a tese, segundo a qual, a doutrina do fato da razão não subverte propriamente nenhuma estratégia argumentativa desenvolvida por Kant anteriormente sobre a questão da fundamentação do princípio supremo da moralidade; e que tal doutrina, situada no próprio limite da razão ${ }^{14}$, assenta em base

${ }^{14}$ Sobre o tema do limite da razão, bem como sua importância para a solução do
problema da justificação de um princípio sintético a priori da razão prática, ver o
excelente artigo do professor C. Hamm, "Sobre o direito da necessidade e o limite da
razão" (Studia Kantiana, vol. 4, n. 1, Nov. 2002). Neste trabalho o professor Hamm
reconstrói a argumentação de Kant acerca da determinação dos limites da razão e de
como a razão, além de aplicar-se ao conhecimento dos objetos da experiência, possui
o "conhecimento (positivo) dos seus próprios limites, os quais nada mais são do que
os limites 'naturais' entre o mundo fenomênico e o mundo numênico" (p. 76). A
demarcação dos limites do uso e do alcance dos conceitos puros do entendimento ou
a delimitação mesma do uso legítimo do entendimento enquanto faculdade do
conhecimento, segundo Kant, implica o reconhecimento de um "espaço" fora do 
estabelecida pela Crítica, contribuindo assim para a conformação do que seria o sistema da razão pura a partir de princípios. Com esta leitura da doutrina do facto da razão, quer-se enfatizar principalmente a perspectiva sistemática que Kant assume ao tomar para si a solução de todos os problemas levantados pela filosofia crítica. Nota-se dessa forma que a noção de limite da razão aponta para um elemento sistematicamente fundamental que nos permite compreender como Kant, por assim dizer, articula a "passagem" da razão pura teórica à razão pura prática.

Efetivamente, na sua tarefa singular de apresentar uma justificação para o princípio supremo da moralidade, o filósofo não pode ignorar os limites da razão estabelecidos pela Crítica da razão pura, o que parece ser enfatizado por ele no argumento final da Terceira Secção da Fundamentação. Todavia, nem por isso o arquiteto da Filosofia Crítica abre mão da validade objetiva do princípio moral supremo, e então, a justificação de tal princípio prático (sintético a priori) não pode ser concebida senão como situada no próprio horizonte da razão, no qual Kant (re)conhece a conexão entre o campo do cognoscível e o campo do incognoscível. É, pois, nesse lugar, sistematicamente relevante, no limite da razão, que Kant pode reconhecer a capacidade legisladora da razão pura e, por isso defender como legítima a concepção de um princípio moral, isto é, um

entendimento mesmo, espaço este "descoberto" na própria razão pela reflexão transcendental e que, embora "vazio" do ponto de vista do uso teórico da razão, é necessário, porque é parte constituinte dos limites do próprio entendimento. De tal modo que a razão pode reivindicar, legitimamente, o conhecimento de seus próprios limites, a saber, o conhecimento da conexão entre o campo do cognoscível e o campo do incognoscível. Trata-se, porém, de um conhecimento por analogia (cf. a respeito, Hamm, p. 73). 
preceito prático com força de lei, ou seja, a concepção de um fato da razão pura.

Isso posto, podemos sustentar que não há uma mudança profunda entre o argumento que Kant apresenta na Fundamentação III e o que ele desenvolve na segunda Crítica para a justificação do princípio da moralidade. Isso porque, tanto em um contexto quanto em outro, ele está articulando a fundamentação do referido princípio no limite da razão. Esta interpretação nos permite compreender além da polêmica que a teoria do facto da razão possa ter gerado (e continua a gerar) no contexto da Filosofia Crítica, pois Kant pôde introduzir, legitimamente, a figura do facto da razão como "instância última" na busca pela justificação do princípio supremo da moralidade. Com efeito, de acordo com a leitura ora proposta, pode-se verificar - o que faremos a seguir - que a doutrina do facto da razão não constitui uma novidade substancial em relação ao exposto na Fundamentação; mais ainda, que tal teoria se encaixa adequadamente às exigências da Filosofia Crítica.

\section{Sobre o argumento de Kant na Fundamentação III}

Ao lermos a Terceira Secção da Fundamentação, podemos ter a impressão de que nesse contexto Kant não avança no terreno próprio da filosofia prática. Já no início do texto, o filósofo propõe: "O conceito da Liberdade é a chave da explicação da Autonomia da Vontade" (FMC, BA 97). Contudo, à medida que a liberdade vai sendo confirmada como pressuposto necessário do princípio supremo da moralidade, também se evidencia a impossibilidade de explicar a realidade objetiva da liberdade, e isso, em pleno acordo com os resultados da primeira Crítica. Ora, estaria assim a "transição da 
metafísica dos costumes para a crítica da razão prática pura”, anunciada por Kant como objeto da última seção da Fundamentação, comprometida? Pois, a impossibilidade de explicar a realidade objetiva da liberdade implica, por consequência, a impossibilidade de explicar “como é possível o imperativo categórico". De modo que o argumento de Kant em prol da liberdade prática nesse contexto parece restringirse tão somente à afirmação de que, se quisermos falar com sentido de moralidade, não podemos renunciar à liberdade, embora também não possamos renunciar à necessidade natural.

Essa reivindicação não é exatamente um argumento e parece que Kant não avança em relação à tese já conhecida acerca da “espontaneidade da razão" ou da ideia transcendental de liberdade. E, note-se, a ideia da liberdade, enquanto absoluta espontaneidade da razão é, de acordo com Kant, no tocante à sua possibilidade, não uma necessidade, mas apenas um princípio analítico da razão pura especulativa (cf. CRPr, A 84). Então, é mesmo preciso perguntar: o que é que o filósofo agrega no argumento da Terceira Secção da Fundamentação para fazer valer a liberdade não mais como um princípio analítico da razão (pura especulativa), mas como um princípio causal (sintético a priori) das ações morais? É certo que o autor aí pretendeu unir ao conceito negativo da liberdade (transcendental) a vontade como faculdade positiva (liberdade prática), como "uma espécie de causalidade" dos entes racionais, como “[...] faculdade de agir de tal modo que o princípio das ações seja conforme ao caráter essencial de uma causa racional, quer dizer, à condição da validade universal da máxima como lei” (FMC, BA 119, grifo meu). Mas, tratar-se-ia justamente de explicar essa (suposta) causalidade da razão pura prática, ou seja, explicar o poder da razão (pura) de determinar o arbítrio de um ente racional finito, 
independentemente de toda e qualquer condição sensível ou matéria do querer! Esta é a questão fundamental da filosofia prática kantiana. A esse respeito a resposta de Kant é negativa.

Nota-se, porém, que essa resposta negativa logo se mostra, pelo menos coerente do ponto de vista mesmo da filosofia crítica, e não mero sinal do (suposto) fracasso de uma tentativa de dedução do princípio supremo da moralidade. Kant tem de reconhecer, nesse contexto, o limite da filosofia prática, esse estabelecido pela própria Crítica, na medida em que, como enfatizado na Crítica da razão pura, o poder explicativo da razão se restringe ao uso empírico dos conceitos puros do entendimento, aplicados aos objetos de uma experiência possível, que são dados (sempre) no espaço e tempo. No que diz respeito ao conceito de liberdade prática, trata-se da aplicação do conceito de causalidade a uma faculdade livre, concebida a priori, e a explicação dessa possibilidade não cabe, por assim dizer, nos limites da razão. Ou seja, desde a perspectiva da filosofia crítica, a explicação propriamente dita, entendida como comprovação de um princípio prático sintético a priori, a qual corresponderia à comprovação mesma da liberdade como princípio causal de nossas ações morais, não pode ser usada como recurso para justificar a validade objetiva de tal princípio. Kant não deixa dúvida a esse respeito.

[Pois] nós nada podemos explicar senão aquilo que possamos reportar a leis cujo objeto possa ser dado em qualquer experiência possível. Ora a liberdade é uma mera idéia cuja realidade objetiva não pode ser de modo algum exposta segundo leis naturais e, portanto, em nenhuma experiência também, que, por consequência, uma vez que nunca se lhe pode subpor um exemplo por nenhuma analogia, nunca pode ser concebida nem sequer conhecida" (FMC, BA 120). 
Por isso, sob risco de contradizer os resultados da investigação transcendental empreendida na primeira Crítica e comprometer o trabalho de mais de uma década, caso afirmasse o contrário, Kant pondera que a liberdade "vale somente como pressuposto necessário da razão num ser que julga ter consciência duma vontade, isto é duma faculdade bem diferente da simples faculdade de desejar (a saber, a faculdade de se determinar a agir como inteligência, por conseguinte segundo leis da razão, independentemente de instintos naturais)" (FMC, BA 120/121). É compreensível que considerações dessa natureza tenham alentado uma interpretação, segundo a qual, o argumento da Terceira Secção da Fundamentação seria uma tentativa fracassada de dedução da lei moral, após considerar que a liberdade em sentido positivo é a única "condição de possibilidade" da lei moral. Assim o reconhecimento de Kant da impossibilidade de explicar como é possível a liberdade pode mesmo sugerir uma tentativa frustrada de apresentar uma dedução da lei moral. Não obstante, o último subtítulo da Fundamentação ("Do Limite Extremo de Toda a Filosofia Prática" BA 113) nos convida, insistentemente, a outra leitura para os (mesmos) argumentos até então apresentados por Kant no contexto da Terceira Secção.

Um elemento, que podemos assinalar como central na dedução do imperativo categórico e proposta na Fundamentação, é o argumento referente à condição de "dupla cidadania" de um ser racional finito, concepção esta amparada no idealismo transcendental. Efetivamente, considerando a distinção dos objetos em geral, em phaenomena e noumena, em relação ao ser humano (cf. FMC, BA 105109), Kant reivindica sua teoria dos dois pontos de vista, sob os quais, o ser racional finito pode ser considerado pertencente ao mundo sensível, mas, como inteligência, membro do mundo inteligível (cf. 
FMC, BA 110). Com a ideia de um mundo inteligível, Kant sustenta o princípio da autonomia da vontade - que tem sua origem no conceito de razão pura em geral. Ressalte-se que, ao referir-se ao mundo inteligível, o filósofo não pretende mais que conceber um ponto de vista que a razão precisa assumir para pensar-se como livre. Pode-se objetar aqui que o puro pensamento de uma ordem inteligível, na qual podemos nos representar apenas pela ideia da liberdade (da vontade) não é suficiente para admitirmos a validade objetiva do imperativo categórico. No entanto, é instigante reconhecer que este pensamento parece tudo o que uma filosofia prática, com pretensões de cientificidade, criticamente delineada, pode oferecer, tanto para "defender o pensamento de uma causalidade agindo livremente", quanto para asseverar sobre a validade objetiva de um princípio prático puro.

Poderíamos assim dizer que tal argumento comporta um aspecto negativo, mas outro (aspecto) positivo: por um lado, ele expressa a impossibilidade de "explicar como é que a razão pura pode ser prática, o que seria a mesma coisa que explicar como é possivel a liberdade" (FMC, BA 120); mas, por outro, Kant conduz seu leitor até às últimas implicações que a natureza mesma da questão acerca de um princípio prático incondicionado admite. E sob a perspectiva crítica assumida pela filosofia kantiana a condução dessa questão até o seu limite é mesmo uma exigência (da razão), e não mero capricho. De tal modo que, de pleno acordo com diretrizes gerais da filosofia transcendental, Kant parece muito à vontade para afirmar que a razão prática nos transpõe para uma ordem inteligível, "uma ordem de coisas totalmente diferente da dos [nossos] apetites no campo da sensibilidade", embora reconheça como forçoso observar que essa operação da razão continua ocorrendo apenas em pensamento. Mais 
do que isso a filosofia crítica não comportaria, mas, tampouco menos! Qualquer outra justificação do princípio da moralidade, entendido como autonomia da vontade, incluída aqui uma justificação nos moldes da dedução das categorias, seria desastrosa para a própria conformação de tal princípio. E é por isso que Kant pode afirmar convictamente que, ao "introduzir-se pelo pensamento em um mundo inteligível, a razão prática não ultrapassa em nada os seus limites [como razão pura]; mas ultrapassá-los-ia se quisesse entrar nesse mundo por intuição, por sentimento" (FMC, BA 118). Note-se então que a argumentação, que pode parecer uma tentativa kantiana fracassada de apresentar uma dedução para o imperativo categórico - nos moldes da dedução dos conceitos do entendimento, se mostra afinal como mérito da Filosofia Crítica, manifestando todo o cuidado do filósofo com a coerência na construção do seu sistema filosófico, situando os argumentos da Fundamentação no horizonte da primeira Crítica.

De acordo com esse horizonte crítico, o que Kant pode oferecer ao seu leitor, no contexto da Fundamentação (III), é somente a defesa da liberdade, mas não uma explicação propriamente dita da realidade da liberdade. Considerando a natureza mesma de um tipo de causalidade espontânea, livre, absolutamente incondicionada, como é o caso da "causalidade por liberdade", ele não pode, comprometido que está com sua filosofia crítica, explicar como é possível a liberdade (se entendermos "explicar" como um modo de demonstração da liberdade operando em nossa vontade como causalidade livre). E, contudo, o filósofo pode muito bem sustentar não só sua possibilidade, como também a necessidade da liberdade como pressuposto de nossas ações morais. Se quisermos encontrar uma razão no texto kantiano que justifique a posição do pensador sobre este aspecto de sua filosofia prática, vamos encontrar sua 
(pre)ocupação em rejeitar o ceticismo moral. Com efeito, que Kant tenha assumido a defesa da liberdade, não obstante as restrições da Crítica quanto à possibilidade de uma dedução estrito sensu deste conceito, mostra todo seu empenho na "repulsão das objeções daqueles que pretendem ter visto mais fundo na essência das coisas e por isso atrevidamente declaram a liberdade impossível" (FMC, BA 121). Com isso, entende-se como uma (espécie de) dedução do imperativo categórico o fato de Kant poder "[...] indicar o único pressuposto de que depende a sua possibilidade, quer dizer a idéia da liberdade", e igualmente poder "aperceber a necessidade deste pressuposto, o que, para o uso prático da razão, isto é para a convicção da validade deste imperativo, e portanto também da lei moral, é suficiente" (BA 124).

A quem, de direito, quiser questionar a legitimidade dessa dedução do imperativo categórico - seja à luz do que Kant nos ensina na primeira Crítica com a dedução das categorias do entendimento ou, tendo em vista a precariedade do conhecimento da razão prática - só uma observação: a liberdade prática transcendental repousa (comodamente!) no limite da razão ${ }^{15}$, este horizonte resultante da investigação transcendental, no qual a razão se mostra como pertencendo tanto à experiência quanto às idéias que delimitam o próprio campo da experiência "por fora". Este é o "terreno aplainado," no qual Kant estabelece o princípio supremo da moralidade como princípio/lei da razão pura. Quanto a saber se, no contexto da Fundamentação (III), o argumento de Kant significa um avanço da

\footnotetext{
${ }^{15}$ Para mais detalhes acerca da fundamentação da moral no limite da razão cf. S. Dejeanne, "A fundamentação da moral no limite da razão em Kant" (tese de doutorado, PUC-RS, 2008).
} 
filosofia prática em relação ao alcance da própria filosofia teórica, parece indiscutível que Kant desenvolve seus argumentos tendo em vista tanto as restrições que a Crítica impôs à razão pura especulativa, quanto a própria capacidade da razão de estabelecer seus próprios limites. E nota-se que é nesse movimento mesmo do pensamento que ele encontra um lugar para a liberdade prática no sistema da razão pura, e, por conseguinte, abre o campo para a Filosofia moral.

Esse quadro interpretativo, no qual aqui lemos o argumento kantiano desenvolvido na Terceira Secção da Fundamentação, parece não ter se mostrado tão facilmente aos contemporâneos de Kant! Com efeito, considerações no Prefácio da segunda Crítica dão conta de que as objeções que se levantaram contra o pensamento moral do filósofo questionavam justamente como ele pôde "contestar realidade objetiva ao uso suprassensível (teórico) das categorias e, contudo, concederlhes essa realidade com respeito aos objetos da razão prática pura" (CRPr, A 8). Kant não ignora as dificuldades implicadas nessa questão, mas parece condescendente com seus críticos:

Compreendo assim também porque é que as objeções mais consideráveis contra a crítica, que até agora encontrei, giram precisamente em torno destes dois eixos: a saber, por um lado, a realidade objetiva das categorias aplicadas a númenos, negada no conhecimento teorético e afirmada no conhecimento prático; por outro, a pretensão paradoxal de fazer de si mesmo um númeno, enquanto sujeito da liberdade, mas ao mesmo tempo também, em vista da natureza, um fenômeno na sua própria consciência empírica (CRPr, A 10).

Ora, tais considerações sugerem que as objeções poderiam ter sido dirigidas à argumentação que Kant desenvolve na Terceira Secção da Fundamentação. Pelo menos, este é o texto que hoje 
conhecemos como o primeiro tratado específico de Filosofia moral do período crítico. Nele Kant apresenta sua proposta crítica de fundamentação do princípio da moralidade, defendendo que o homem enquanto ser numênico é sujeito da liberdade. Se essa leitura estiver correta, então as considerações supracitadas também contribuem para o entendimento de que, na Crítica da razão prática, o filósofo trata justamente de esclarecer sua posição já definida e assumida em 1785 , mas não de buscar uma solução nova para o problema da fundamentação do princípio supremo da moralidade. E é nessa configuração que se pode encaixar a doutrina do fato da razão, que, em que pese sua novidade, parece cumprir à perfeição o intento de Kant de definir a lei moral como uma lei da razão prática pura. Tratase aqui, pois, de mostrar que a doutrina do fato da razão, apresentada por Kant na segunda Crítica, acomoda perfeitamente bem sua reivindicação de uma "lei da razão" da qual não podemos prescindir, mas a qual não é possível explicar.

Sobre a doutrina do facto da razão como expressão crítica da capacidade legisladora da razão pura em seu uso prático

Na secção da Crítica da razão prática intitulada "Da dedução dos

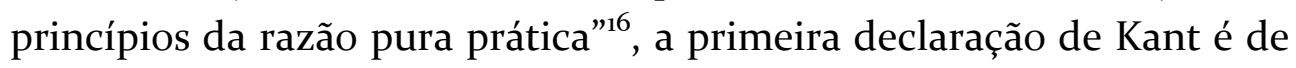
que "Esta analítica mostra que a razão pura pode ser prática, isto é, determinar a vontade por si mesma, independentemente de todo o elemento empírico - e mostra isso mediante um facto (Faktum) em que a razão pura se evidencia efectivamente em nós como prática,

${ }^{16}$ Cf. CRPr, A $72-87$.

Diaphonía, ISSN 2446-7413, v. 1, n. II, 2015 
determinando por este meio a vontade à acção" (CRPr, A 72) ${ }^{17}$. A questão é como entender exatamente essa afirmação, pela qual Kant diz ter mostrado que a razão pura pode ser prática mediante um facto em que a razão pura se evidencia efetivamente em nós como prática ${ }^{18}$.

Nos primeiros §§ da Analítica, Kant reitera o argumento já apresentado na Fundamentação de que uma lei prática incondicionada, para ser concebida e admitida como tal, requer a diferença de meros preceitos práticos, a eliminação de toda e qualquer condição empírica, entenda-se isso como (condição) material do fundamento determinante da vontade. De modo que uma lei prática incondicionada, se tal é possível, há que ser concebida como uma lei

${ }^{17}$. A tradução usada no texto é de Artur Morão (Edições 70), que difere um pouco da tradução de Valério Rohden (Martins Fontes): "Esta analítica demonstra que a razão pura pode ser prática - isto é, pode determinar por si a vontade independente de todo o empírico -, e isto na verdade mediante um factum, no qual a razão pura deveras se prova em nós praticamente, a saber, a autonomia na proposição fundamental da moralidade, pela qual ela determina a vontade ao ato".

${ }^{18}$ Guido de Almeida, no seu artigo "Kant e o 'facto da razão': 'cognitivismo' ou 'decisionismo' moral?" (Studia Kantiana, vol. 1, n. 1, set/1998), aborda a dificuldade da interpretação desta figura argumentativa introduzida por Kant na segunda Crítica e sua adequação ao sistema crítico. De acordo com Almeida, na CRPr Kant teria apresentado uma "[...] importante modificação de sua teoria, a qual se resume, agora, em dois passos sumários. O primeiro [é] o reconhecimento formal, consignado já no Prefácio da obra, de que, embora a liberdade seja a ratio essendi da moralidade, esta é a ratio cognoscendi da liberdade da nossa vontade, o que de antemão implica o abandono do tipo de dedução proposto na FMC" (p. 56). Ora, mesmo admitindo que na FMC Kant tenha tentado explicar a lei da autonomia da vontade pelo conceito de liberdade, seu reconhecimento da "impossibilidade de 'inferir por raciocínios subtis' a consciência da lei moral da consciência da liberdade como um 'dado anterior da razão" pode não ser visto como reconhecimento de uma tentativa fracassada de deduzir a lei moral do conceito de liberdade. Antes, pode ser lido como o reconhecimento do "limite extremo de toda filosofia prática", o qual parece não poder ser alargado com a doutrina do facto da razão. 
formal da razão pura. E sobre o caráter formal da lei moral, o leitor de Kant também já está informado pela Fundamentação. Este tema simplesmente é retomado e desenvolvido na Crítica da razão prática, a partir do § 2. Teorema I (A 38), no qual uma vez mais lemos que uma lei prática pode ser concebida apenas como uma lei formal da vontade (cf. A 41). Ao retomar o tema da Segunda Secção da Fundamentação, o autor reitera que nenhum princípio prático material pode ser definido como uma lei prática. Consequentemente, "se um ente racional deve representar suas máximas como leis universais práticas, então ele somente pode representá-las como princípios que contêm o fundamento determinante da vontade não segundo a matéria, mas simplesmente segundo a forma" (CRPr, A 48).

Sabemos então que Kant descarta como candidatos a uma lei prática (moral) todos os princípios práticos materiais (mais precisamente preceitos práticos - e não leis) que, enquanto tais são "no seu conjunto de uma e mesma espécie e incluem-se no princípio geral do amor de si ou da felicidade própria" (CRPr, A 40). Como nenhum princípio condicionado empiricamente pode constituir-se em lei prática, ou seja, em um princípio universalmente válido, o filósofo pondera que "um ente racional ou não pode absolutamente representar seus princípios prático-subjetivos, isto é, suas máximas, ao mesmo tempo como leis universais, ou tem de admitir que a simples forma dos mesmos, segundo a qual eles convêm à legislação universal, torna-os por si só uma lei prática" (A 49). Agora, se a forma da lei pode ser representada exclusivamente pela razão, compreende-se que "a representação dessa forma como fundamento determinante da vontade é diferente de todos os fundamentos determinantes dos eventos na natureza segundo a lei da causalidade" (A 51). Em todas essas considerações na segunda Crítica, nenhuma novidade em relação 
à argumentação desenvolvida na Fundamentação, e nenhuma prova demonstrativa da validade dessa lei que só pode ser representada pela razão. Mesmo assim Kant sentencia:

Podemos tornar-nos conscientes de leis práticas puras do mesmo modo como somos conscientes de proposições fundamentais teóricas puras, na medida em que prestamos atenção à necessidade com que a razão as prescreve a nós e à eliminação de todas as condições empíricas, à qual aquela nos remete. $\mathrm{O}$ conceito de vontade pura surge das primeiras, assim como a consciência de um entendimento puro, das últimas (CRPr, A 53).

Basicamente, o que lemos aqui é que a lei fundamental da razão pura prática, expressa na fórmula do Imperativo Categórico: "Age de tal modo que a máxima de tua vontade possa sempre valer ao mesmo tempo como princípio de uma legislação universal" (CRPr, A 54), mesmo quando não rigorosamente observada, impõe-se à consciência de entes racionais finitos, não sem prejuízo para as suas inclinações ${ }^{19}$. Kant procura ilustrar com exemplos a consciência do dever moral, ou seja, a consciência do que se deve fazer incondicionalmente enquanto ente racional. Mas o que ele não consegue demonstrar de modo algum é o que está pressuposto na base desse "dever", a saber, (a consciência de) um princípio puro da razão, da capacidade legisladora da razão prática (pura), que se impõe ao arbítrio humano como dever precisamente na medida em que este arbítrio é também afetado por desejos e inclinações sensíveis.

Com efeito, de acordo com a ética kantiana, o dever moral que se apresenta à vontade humana não é outra coisa senão uma exigência da

\footnotetext{
${ }^{19} \mathrm{Cf}$. a esse respeito os exemplos de Kant em CRPr, A 54 .
} 
DEJEANNE, $\mathrm{S}$.

razão que se eleva acima das inclinações e manifesta assim sua capacidade legisladora, por isso concebida por Kant como razão prática pura. A questão é que não é possível demonstrar como a razão pura pode ser prática, e mesmo assim a consciência do dever moral revelaria, por assim dizer, que a razão prática tem uma lei. Para Kant, "[p] ode-se denominar a consciência desta lei fundamental um factum da razão, porque não se pode sutilmente inferi-la de dados antecedentes da razão [...]" (CRPr, A 55-6). A lei moral é a lei, segundo a qual, "uma <razão> pura, em si razão prática, é aqui imediatamente legislativa" (CRPr, A 55). Enfim, da Analítica da razão prática Kant faz a lei moral, por assim dizer, emergir como uma lei cujo conteúdo parece ser a própria forma legisladora da razão. Ora, esta lei formal da razão pura, por sua vez, pode ser admitida apenas como uma "lei da liberdade". Portanto, somente quando a vontade se encontra sob o conceito da liberdade seus princípios se chamam leis ${ }^{20}$.

Nota-se então que, na Crítica da razão prática, fica explícito que a lei moral, um princípio incondicionado, e a liberdade em sentido positivo, como propriedade da vontade "dos seres vivos, enquanto racionais", referem-se mutuamente. Todavia, tampouco essa "reciprocidade" é novidade, pois ela já pode ser observada na Fundamentação da metafísica dos costumes. É claro que, tanto quanto se pode perceber, na Fundamentação Kant não apresenta nenhuma

${ }^{20}$ Cf. Crítica da Faculdade de Julgar (CJ), Introdução, XIV. E em CJ, XV: "as prescrições moral-práticas, que se fundam por completo no conceito de liberdade, excluindo totalmente os princípios de determinação da vontade a partir da natureza, constituem uma espécie absolutamente particular de prescrições, as quais, por semelhança com as regras a que a natureza obedece, se chamam pura e simplesmente leis. No entanto, não assentam como estas (as regras a que a natureza obedece) em condições sensíveis, mas sim num princípio supra-sensível [...]”.

Diaphonía, ISSN 2446-7413, v. 1, n. II, 2015 
inferência da consciência da liberdade para a consciência da lei moral, e nem desta para aquela. De modo que o que o filósofo tem em mão, antes de definir (e estabelecer!) a lei moral como facto da razão, é apenas a ideia da liberdade como pressuposto necessário da Autonomia da Vontade, mas não (tem) ainda a (prova da) realidade mesma da liberdade como "princípio causal" das ações morais. E poderia alegar-se que nisso consistiria a principal diferença entre os dois (con)textos em questão. Todavia, parece que nem aqui encontramos uma diferença essencial na teoria de Kant. Vejamos!

No texto de 1788 , lemos que a operação de derivar da liberdade da vontade (em sentido positivo) a lei moral "[...] requereria como conceito positivo uma intuição intelectual, que aqui de modo algum se pode admitir" (CRPr, A 56). Ora, assim como a (consciência da) lei moral não pode ser simplesmente inferida do conceito de liberdade, ela tampouco pode ser objeto da intuição empírica. Com isso, reiterase que a consciência da lei moral não pode ser derivada de modo algum de dados antecedentes da razão, pois, se esse fosse o caso, não teríamos, como visto anteriormente, uma lei prática, mas antes um preceito, isto é, uma regra prática condicionada. Por isso, no caso de uma proposição prática, moralmente válida, "a regra diz: deve-se simplesmente proceder de certa maneira" (CRPr, A 54), porque "a regra prática é incondicionada, por conseguinte representada a priori como proposição categoricamente prática, pela qual a vontade é absolutamente e imediatamente determinada (pela própria regra prática, que portanto aqui é lei)" (A 55 - grifos meus).

É mesmo notável que a tarefa da justificação do princípio supremo da moralidade seja enormemente dificultada pelas restrições já conhecidas da Crítica da razão pura. Talvez não por outro motivo, 
senão para reunir em um único conceito este quadro bastante incomum de considerações sobre a natureza de uma lei prática, Kant pondera: "Pode-se denominar a consciência desta lei fundamental um factum da razão [...] porque ela se impõe por si mesma a nós como uma proposição sintética a priori [...]”; mais ainda, "para considerar esta lei como inequivocamente dada, precisa-se observar que ele não é nenhum fato empírico mas o único factum da razão pura, que deste modo se proclama como originariamente legisladora" (CRPr, A 55-56). Uma pergunta que se pode fazer a propósito, já não sem resposta(s) na literatura, é sobre a natureza mesma do facto da razão: consciência da lei ou a própria lei?

Parece-nos que Kant designou a lei moral como "facto da razão", senão por outro motivo, porque essa lei é de uma natureza tal que transcende os limites de toda a experiência possível. Daí sua posição com relação a tal lei. Posição essa que, em essência, já é delineada no argumento da Fundamentação: "Ora, não pode explicar-se mais como é possível esta consciência da lei moral, ou, o que é a mesma coisa, a da liberdade, somente pode defender-se a sua admissibilidade na crítica teórica" (CRPr, A 79-80).

Por fim, podemos perguntar: com que direito Kant pode apresentar sua doutrina do facto da razão como solução para o problema da fundamentação da metafísica dos costumes, e, por conseguinte, o "lugar" para conhecer a liberdade como propriedade da vontade, como "uma espécie de causalidade dos seres vivos, enquanto racionais"? O que Kant estabelece efetivamente com a doutrina do facto da razão? Que a autonomia da vontade é o princípio da moralidade? Ou que a vontade é autônoma? Será que, com a doutrina do facto da razão, Kant pretende apenas mostrar efetivamente que a 
vontade é autônoma? Modestamente, penso que, com a doutrina do facto da razão, Kant está simplesmente a afirmar ou a reafirmar que a autonomia da vontade, já reconhecida na Fundamentação como o princípio da moralidade, só pode ser concebida como um facto da razão pura, ou seja, como um princípio da razão pura em seu uso prático; e que isso significa exatamente que não se pode mostrar a autonomia da vontade, porque esta tarefa transcende os limites do conhecimento possível, embora não transcenda os limites da própria razão, pois, se a liberdade é a ratio essendi da lei moral - e segundo Kant o é - como explicar esse princípio da razão? Isso equivaleria a esclarecer como é possível a liberdade! Mas, para isso, Kant teria que explicar a liberdade a partir de "condições naturais", extrínsecas à própria liberdade, o que é, por definição, um absurdo de acordo com a Filosofia Crítica.

\section{Referências bibliográficas}

ALMEIDA, G. de. “Kant e o 'facto da razão': 'cognitivismo' ou ‘decisionismo' moral?”, Studia Kantiana, vol. 1, n. 1, 1998.

CORTINA ORTZ, A. "Estudio Preliminar" a La Metafísica de las Costumbres”, in.: Kant, I. La Metafísica de las Costumbres. Trad. Adela Cortina e Jesus Conill Sancho. Madrid: Tecnos, 1989.

DALBOSCO, C. “'Círculo vicioso' e idealismo transcendental na Grundlegung”, Studia Kantiana, vols. 6/7, 2008.

DEJEANNE, S. A fundamentação da moral no limite da razão em Kant, PUC/RS, 2008 (Tese de doutorado).

FAGGION, A. "A doutrina do facto da razão no contexto da filosofia crítica kantiana”, Studia Kantiana, vol.6/7, 2008.

HAMM, C. "Sobre o direito da necessidade e o limite da razão", Studia Kantiana, vol. 4, n. 1, 2002. 
KANT, I. Fundamentação da metafisica dos costumes. Trad. Paulo Quintela. Lisboa: Edições 70, 1994.

. Crítica da razão prática. Trad. Artur Morão. Lisboa: Edições 7o, 1994.

. Crítica da razão pura. Trad. Alexandre Fradique Morujão e Manuela Pinto dos Santos. 3 ed. Lisboa: Calouste Gulbenkian, 1994. . Crítica da razão prática. Trad. Valério Rohden. São Paulo: Martins Fontes, 2002.

. Crítica da Faculdade do Juízo. Trad. Valério Rohden e António Marques. 2 ed. Rio de Janeiro: Forense Universitária, 2010.

LOPARIC, Z. "O Fato da razão - uma interpretação semântica". Analytica, vol. 4, n . 1, 1999. 